Short Review

\title{
Carbon Dots: An Insight into Their Application in Heavy Metal Sensing
}

Carlos A. Echeverry-Gonzalez ${ }^{1,2,+}$, Vladimir V. Kouznetsov ${ }^{1,+*}$

1. Laboratorio de Química Orgánica y Biomolecular, CMN, Universidad Industrial de Santander, Parque Tecnológico Guatiguará, Km 2 vía refugio, Piedecuesta, A.A. 681011, Colombia; E-mails: caecheverry@gmail.com; kouznet@uis.edu.co

2. Laboratorio de Química Orgánica Aplicada, Universidad Manuela Beltrán, Cl. 33 \# 26-34, Bucaramanga, A.A. 680002, Colombia

$\dagger$ These authors contributed equally to this work.

* Correspondence: Vladimir V. Kouznetsov; E-Mail: kouznet@uis.edu.co

Academic Editor: Hossein Hosseinkhani

Special Issue: Nanosensors: Recent Advances and Future Trends

Recent Progress in Materials

2021, volume 3, issue 2

doi:10.21926/rpm.2102015
Received: December 01, 2020

Accepted: April 15, 2021

Published: April 28, 2021

\begin{abstract}
The design of nanomaterials for application in diverse fields ranging from photovoltaic to fluorescence sensing is a research area of increasing interest. Recently, Quantum Dots (QDs), which are classified as semiconductor quantum dots (SQDs) and Carbon dots (CDs), have become a hot topic of investigation, owing to their extraordinary tunable fluorescence emission properties that render them excellent candidates for sensing metal ions. The detection of metal ions in aqueous solutions with high sensitivity is very important as these ions have toxicological and environmental impacts. In this short review, we have described the fluorescence emission properties of $\mathrm{CDs}$ and their application for the detection of different metal ions, such as $\mathrm{Hg}^{2+}, \mathrm{Pb}^{2+}, \mathrm{Cu}^{2+}, \mathrm{Fe}^{3+}, \mathrm{Cd}^{2+}$, and $\mathrm{Cr}^{6+}$.
\end{abstract}

\section{Keywords}

Quantum dots; carbon dots; semiconductor quantum dots; graphene quantum dots; metal ion sensing; tunable fluorescence emission

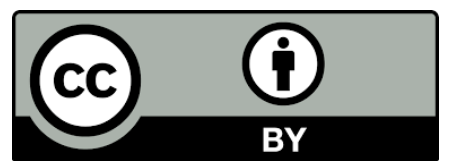

(C) 2021 by the author. This is an open access article distributed under the conditions of the Creative Commons by Attribution License, which permits unrestricted use, distribution, and reproduction in any medium or format, provided the original work is correctly cited. 


\section{Introduction}

In the last decade, the development of novel functional electronic devices had gained much attention owing to the increasing problems regarding energy consumption and fossil fuels. These electronic devices are made from organic, inorganic, and combined organic-inorganic materials, and offer the possibility of tunable long-term stability, conductivity, and photoluminescence properties through subtle structural changes that resulted in wide-range applications, such as photovoltaic (PV) [1], artificial photosynthesis [2], and Organic Light-Emitting Diodes (OLEDs) [3].

Among these electronic devices, nanomaterial-based devices gained increasing interest because their sizes are in the quantum-confined regimen with at least one dimension less than $10 \mathrm{~nm}$ and their excitons are confined in spatial dimensions with quantized energy states resulting in great physicochemical properties $[4,5]$. An example of this kind of nanomaterials would be the fluorescent quantum dots (QDs), which are applicable in a broad range of fields, such as bio-labelling [6], bio-imaging [7], drug delivery [8], biochemical sensing [9], and photodynamic therapy [10]. QDs were first described by Ekimov and Onushenko [11] by exploring the size effects on the exciton absorption spectrum of $\mathrm{CuCl}$ crystals' growth in a transparent dielectric matrix (glass matrix). However, the term "Quantum Dot" was coined by Reed and co-workers, referring to nanoparticlebased semiconductors [4, 12]. Thus, the first class of these nanomaterials corresponded to semiconductor quantum dots (SQDs) that were obtained from the group 13 and 14 elements (e.g., gallium-, indium-, silicon-, germanium-, and lead-based QDs). However, colloidal methods were used for synthesizing the QDs by combining a transition metal, such as zinc, cadmium, and mercury, with the representative elements such as sulphur, selenium, or tellurium [13,14]. Another class of QDs is based on carbon (CQDs), which have received great attention in the last two decades because of their optoelectronic properties. According to Valcárcel and co-workers [4], CDs could be classified in carbon nanodots (CNDs, nanodots that lack quantum confinement), carbon quantum dots (CQDs, nanodots with quantum confinement and a crystalline structure), and graphene quantum dots (GQDs, which use a $\pi$-conjugated single sheet of graphene with quantum confinement).

The increasing interest in QDs has been reflected in the huge number of papers published in this field since the first original report by Ekimov and Onushenko. According to the SciFinder search performed by our team, in the last two decades, the number of publications introducing the term QDs in the articles' titles has increased considerably, with a peak of 9563 publications reached in 2019. Likewise, the number of publications using the term CQDs in their titles has also increased since their discovery in 2004 (Figure 1). 


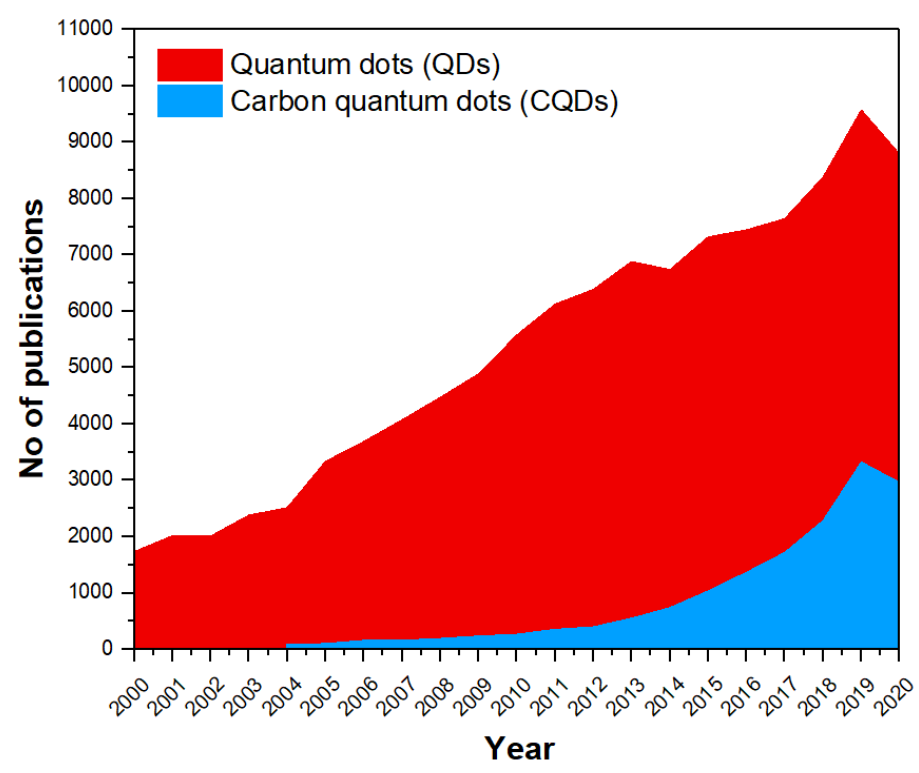

Figure 1 Number of publications on QDs and CQDs since 2000, according to SciFinder database

This review is specifically focused on the fluorescent CDs, which include all three groups mentioned above (CNDs, CQDs, and GQDs), and their application in heavy metal fluorescence sensing. We conducted a comprehensive survey on the important aspects of CDs, including their design, fabrication, principal features, optical properties, and the applications of their fluorescence emission for the detection of metal ions in aqueous solutions with demonstrated toxicological and environmental impact. Accordingly, we could provide an overview of the status of these applications.

\section{Synthesis and General Properties of the CDs}

CDs are novel nano-sized carbon particles (size $<10 \mathrm{~nm}$ ) with extraordinary features, such as nontoxicity, high quantum yield (QY) with a tunable bandgap, photostability, low cost, and high surface passivation [15]. Despite these advantages, it is worth mentioning that CDs show some disadvantages in comparison to SQDs that limit their applications, such as difficulties in preparation, purification, and characterization. In addition, they often provide low quantum yields and certain ambiguity in their geometry and structure $[16,17]$.

CDs can be classified as CNDs, CQDs, and GQDs depending on their nature, crystalline structure, and quantum confinement as mentioned above, which, in turn, depend on the different precursors and synthesis methods used for their fabrication (Figure 2) [18]. CNDs are carbon-based nanoparticles that lack crystalline structure as well as quantum confinement; the carbon core is a disordered mixture of mostly $\mathrm{sp}^{3}$ carbons. Different top-down and bottom-up strategies have been reported for the synthesis of CNDs. However, it is very difficult to control their structure and size $[19,20]$. CQDs have a quasi-spherical structure with a carbon crystalline core based on $\mathrm{sp}^{2}$ and $\mathrm{sp}^{3}$ carbons and quantum confinement. In contrast, GQDs are $0 \mathrm{D}$ materials that possess a well-defined crystalline structure comprising metallic atoms and nanosheets of $\mathrm{sp}^{2}$ carbons [4] with the specific characteristics that are derived from graphene and CDs [21]. Therefore, GQDs have gained special attention in the scientific community. Certain characteristics of GQDs, such as FLE properties (excitation-dependent FLE, functionalization-dependent FLE), biocompatibility, low toxicity, very 
high thermal conductivity, good electron mobility, superior mechanical flexibility, and high photostability (non-photo-bleaching and non-photo-blinking) have increased their application as biomedical sensors [22], environmental detection of heavy metal ions [23], and drug delivery systems for anticancer therapy [24].

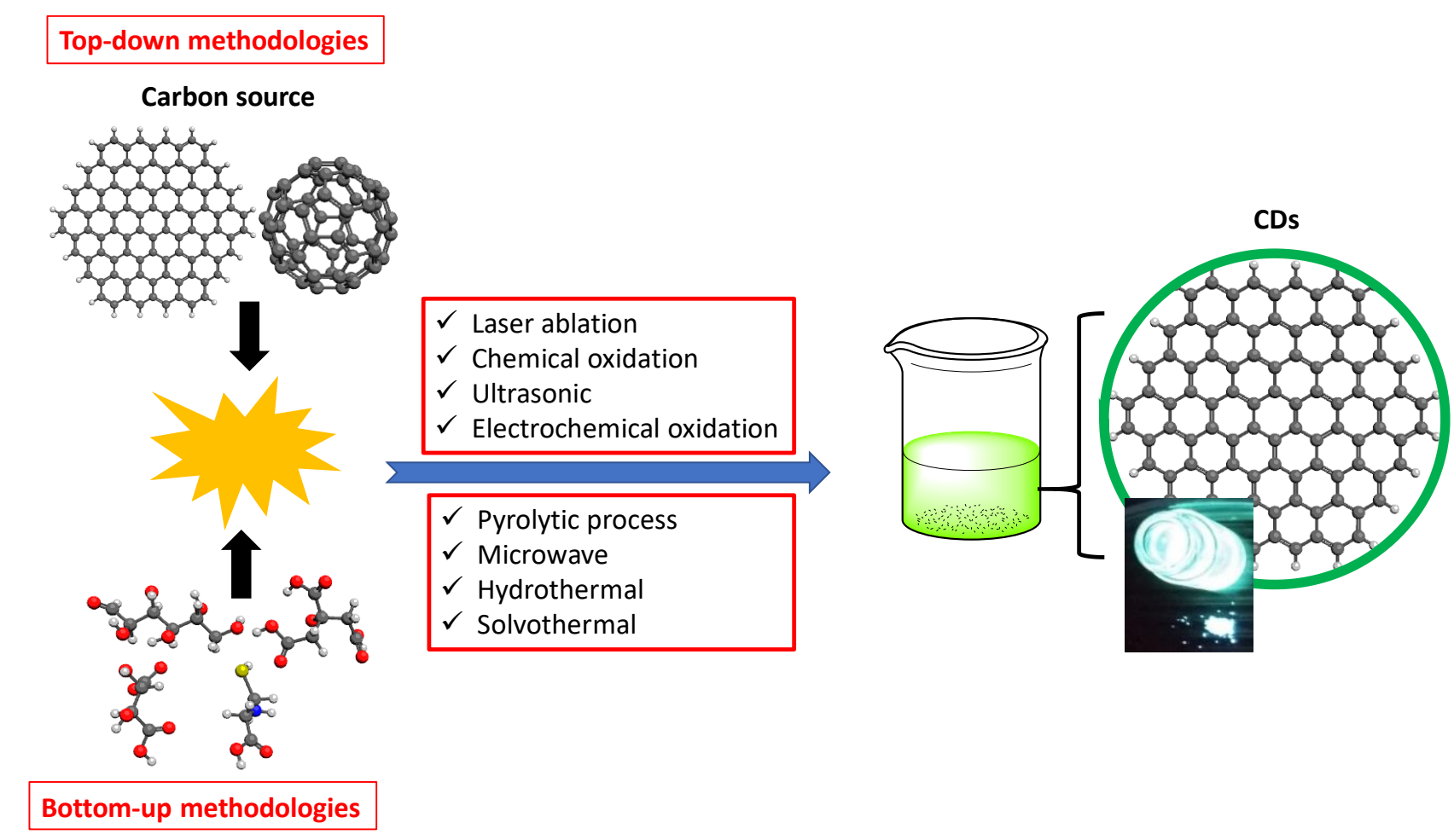

Figure 2 Schematic example of top-down and bottom-up methodologies for producing CDs

Regarding preparation, different synthetic methods using either top-down or bottom-up methodologies have been reported for obtaining high yields of CDs with high purity, suitable particle size, and better luminescence behaviour (Figure 2) [25]. Top-down methodologies include protocols in which carbon sources break down to generate $C D$ s, while bottom-up methodologies happen via the chemical fusion of small aromatic molecules through pyrolysis or carbonization. In the top-down methodologies, the most commonly used methods are laser ablation [26, 27], chemical oxidation using acid-refluxing methods [28], ultrasonic treatment [29, 30], and electrochemical oxidation [31, 32 ]. On the other hand, the bottom-up methodologies include the classic pyrolytic process and microwave technique [33-36].

The investigation of novel CDs with different passivation agents has improved their photophysical properties while maintaining their low toxicity. For example, the application of CDs in light-emitting diode (LED) technology is an area of increasing interest due to its efficiency in energy consumption [37-39]. The most important component of LED devices is a sandwich-type structure known as the emitting layer, which is made of different organic and organic-inorganic materials with extraordinary emission properties, high photostability, and optimal external quantum efficiency (EQE) [3, 40]. Recently, the use of organic materials for fabricating OLEDs has gained immense research interest as these materials are cheaper, thinner, more efficient, and more flexible than the other technologies used before. However, the use of fluorescent organic 
compounds leads to poor colour purity because these materials exhibit a broad fluorescence emission with a full-width at half-maximum (FWHM) of $>60 \mathrm{~nm}$ [41]. Therefore, the synthesis of novel materials showing narrow FWHM with high EQE is the current field of research with several pitfalls. As the first approach, colloidal SQDs based on $\mathrm{Cd}^{2+}$ were obtained with an efficient deepblue emission, and quantum yields (QYs) of over $70 \%$, EQE of $8.05 \%$, and brightness of $62,600 \mathrm{~cd}$ $\mathrm{m}^{-2}$; however, the toxicity of $\mathrm{Cd}$ limited their applications [42]. Considering that, Sargent and coworkers synthesized deep-blue CDs from citric acid as the carbon source and diaminonaphthalene as the passivation agent, which afforded a QY of $70 \% \pm 10 \%$, EQE of $4 \%$, and brightness of $2,240 \mathrm{~cd}$ $\mathrm{m}^{-2}$. Interestingly, these CDs showed high colour purity considering the narrow FWHM of $\sim 35 \mathrm{~nm}$ [43].

\subsection{Fluorescence Emission in CDs}

At this point, it is important to mention that all CDs carry similar absorption and fluorescence properties regardless of their synthetic procedure; a typical absorption in the UV region (230-320 $\mathrm{nm}$ ) corresponding to $\pi-\pi *$ transitions of the carbon core and $n-\pi *$ from the different connected groups, such as $\mathrm{C}=\mathrm{O}[44]$, suggests a similarity in the structure and peripheral groups in various $\mathrm{CDs}$ [45]. The fluorescence emission (FLE) in CDs is currently an important topic of discussion because the exact mechanism of this emission is not yet completely understood. Likewise, another important feature of CDs corresponds to the dependence of the fluorescence emission on the excitation wavelength $\left(\lambda_{\text {exc }}\right)$, which is known as wavelength-dependent behaviour or giant red-edge effect [46]. This behaviour in organic dyes and inorganic complexes results from a variety of solute-solvent interactions in the ground and excited states under the conditions of restricted mobility $[47,48]$. This phenomenon does not fit with Vavilov's law and Kasha's rule, which state that the emission energy is independent of the excitation energy within the absorption band and that fluorescence normally occurs from the lowest vibrational level of the first excited electronic state, respectively [49]. This could be attributed to different factors, such as solvation effects and wide distributions of the sized dots and surface [44]. Figure 3 summarizes a schematic mechanism for the tunable FLE in CDs in which the presence of the particles of different sizes and different emissive sites on the surface of the CDs result in multi-colour emission; it also shows the dependent behaviour of the emission peaks on $\lambda_{\text {exc. }}$ It is worth noting that this tunable emission in a wide range of the visible spectrum shown by the CDs results in surface passivation wherein the surface defects are stabilized, leading to the emission with high quantum yields [16]. 

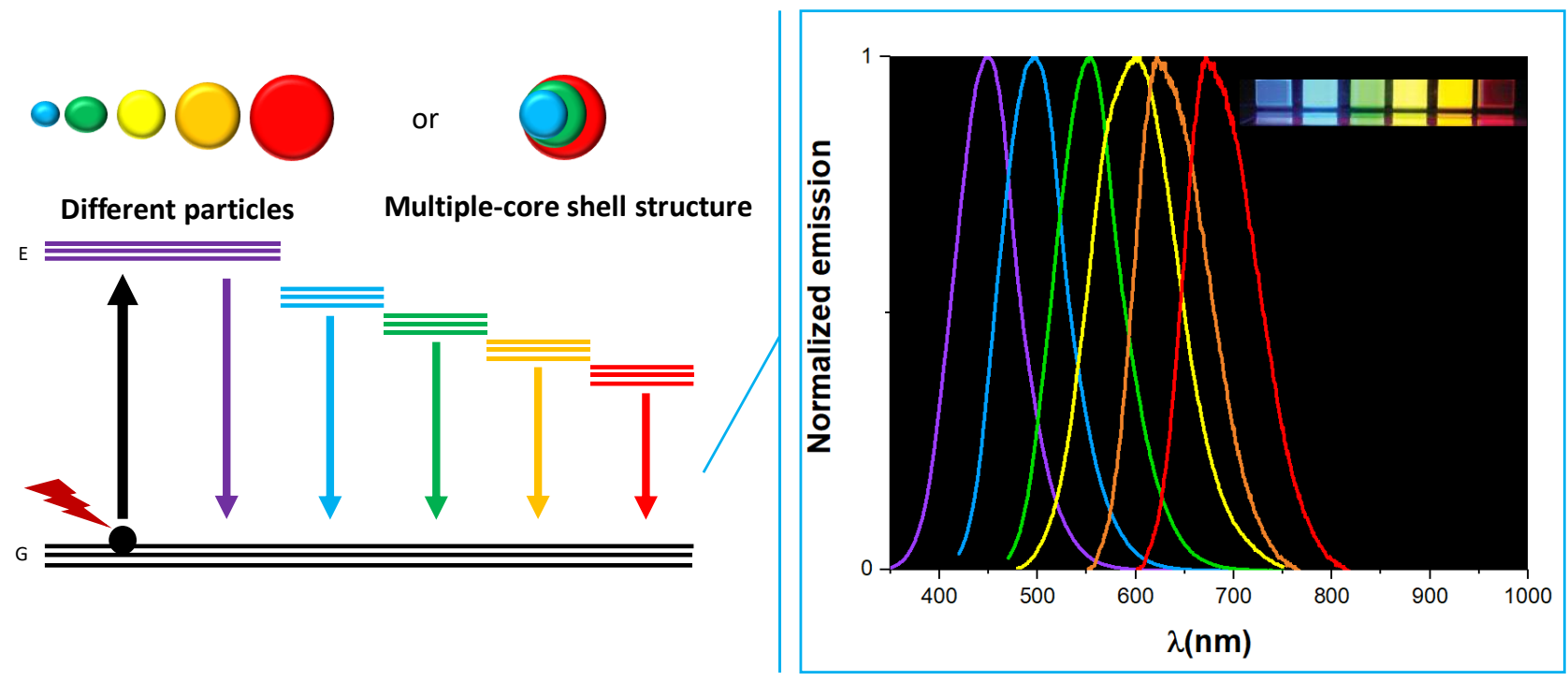

Figure 3 Emission features of CDs.

Different origins for FLE in CDs have been explored; however, those from the presence of different particles and multiple-core shell structures have a high grade of acceptance (Figure 3 ). The first one is based on the band-gap transitions caused by conjugated $\pi$-domains, while the second one considers that the presence of surface defects in CDs are responsible for the high efficient emission [16]. Gao and co-workers [50] studied the origin of the multi-emission luminescence in CDs, which was obtained from a mixture of 2,4-diamine toluene, ethylenediamine, and phosphoric acid through the bottom-up approach by heating at $195{ }^{\circ} \mathrm{C}$ for $9.5 \mathrm{~h}$. Multi-emission CDs showed three different emission peaks at 350,420 , and $520 \mathrm{~nm}$, which were $\lambda_{\text {exc }}$-dependent, with excitation ranging from $260-480 \mathrm{~nm}$. The FLE mechanisms were clarified mainly using time-resolved emission spectra, which revealed that the high-energy peak was associated with the band-gap transitions caused by the conjugated $\pi$-domains (carbon core); the peak at $420 \mathrm{~nm}$ was attributed to the surface defects and the peak at $520 \mathrm{~nm}$ corresponded to the aggregated molecular state. In this case, an important conclusion was that the multi-emission luminescence originated from multienergy states resulting from the presence of three kinds of CDs. However, these emission phenomena not only restricted the presence of different particles but also prevented the presence of multiple-core shell structures (different emissive sites, Figure 3). Lü and co-workers reported the synthesis of multiple-core shell structured CDs via the hydrothermal method from 5-amino-1,10phenanthroline and citric acid, which showed triple emission in blue, green, and red regions coming from the core, edge, and surface bands [51].

Thus, FLE is the main feature of CDs and responsible for their application in different fields. Considering that, we highlight the applications of $C D$ fluorescence properties, specifically the applications in biochemical sensing [52]. Fluorescence-based sensing has become an active area of interest in recent years due to its ability to easily recognize varied target molecules or ions using versatile sensory materials with high sensitivity and excellent linear response. Different organic and organic-inorganic materials have been employed as fluorescent sensors, including complexes [53, $54]$, dyes [55, 56], heterocyclic compounds [57, 58], etc. Likewise, it has been demonstrated that the use of these organic sensors improves the catalytic activity for detecting the target metals [59]. 
A recognition unit contains within the structure of sensory material, which results in certain fluorescence changes upon contacting the target species; the changes in fluorescence include changes in the intensity, emission peak position, total quenching, anisotropy, or lifetime [60]. Total quenching of fluorescence (turn-off mode) and fluorescence recovery (turn-on mode) are the most extensively used principles for sensory applications, in which different mechanisms leading to fluorescence turn-on and turn-off may occur depending on the interaction with the target ions or molecules.

Figure 4 summarizes the mechanisms that commonly lead to fluorescence turn-on and turn-off, which include: i) The photo-induced electron transfer, PET; it occurs through an internal deactivation process involving electronic interaction between the excited state of the recognition unit (fluorophore) and the target molecule; ii) The photo-induced charge transfer, PCT; the fluorescence changes occur by the interruption of the electronic coupling between the donor and acceptor moieties; iii) the Föster resonance energy transfer, FRET; this is a process in which deactivation of an excited molecule transfers the energy to another molecule to excite it; iv) Ratiometric dual emission, RDE; It happens in the presence of two non-overlapping emission peaks that respond independently to the target analytes, and $v$ ) Inner filter effect, IFE; it occurs when the absorption of excitation and/or emission radiation happens by a sample matrix and reduces the fluorescence intensity, thereby resulting in a lower QY [61, 62].

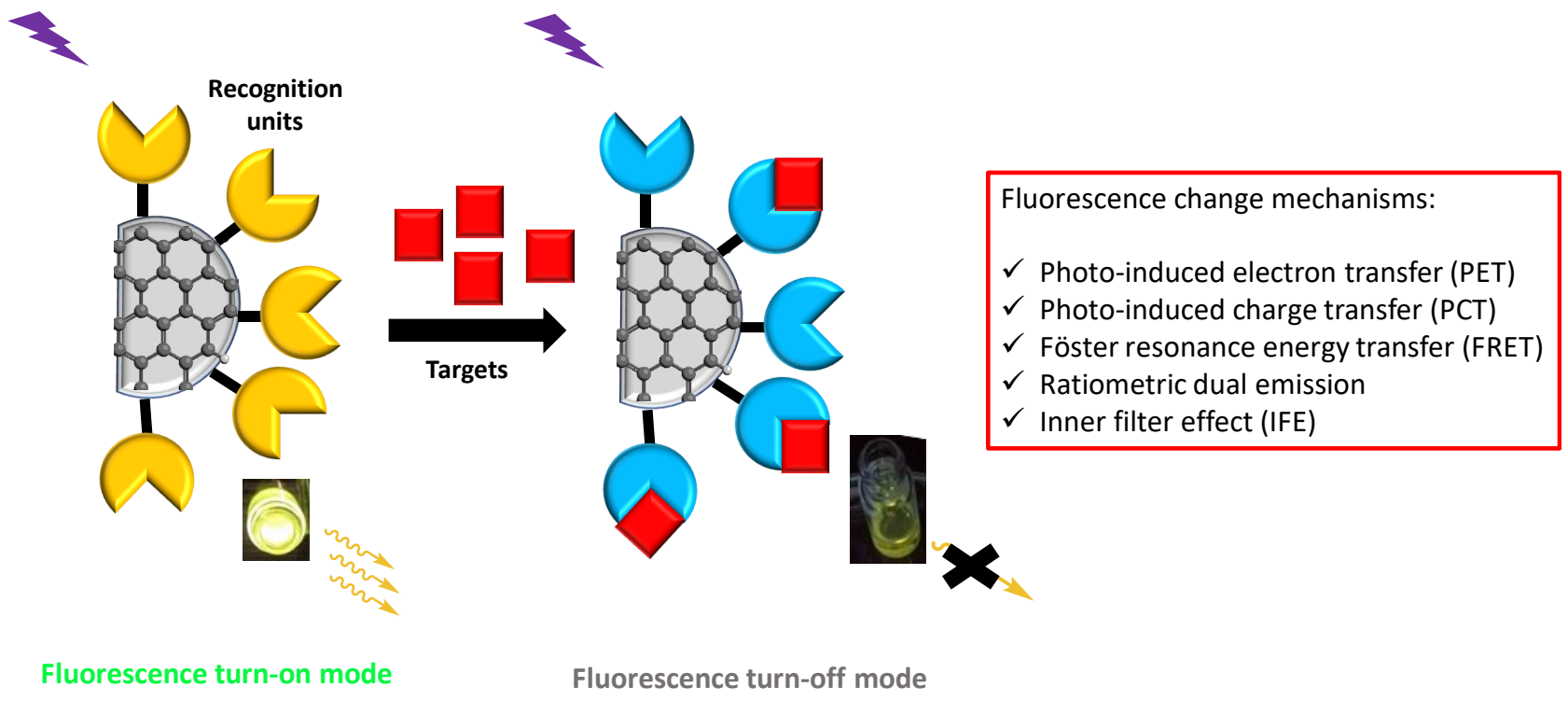

Figure 4 Schematic example of the application of CDs in fluorescence-based sensing.

In some cases, the design of the sensory materials that recognize the target analytes with high sensibility is a complicated aim owing to the difficulties of building the right structure using the correct energy-transfer mechanisms. A good example of the design of a sensing probe was reported by Wang and co-workers [63]. For the detection of tetracyclines, they described the synthesis and characterization of a sensor that was based on boron nitride QDs and Europium ions $\left(\mathrm{Eu}^{3+}\right)$. Tetracyclines are broad-spectrum antibiotic compounds extensively used for the prevention and control of microorganisms. The QDs showed a maximum FLE peak at $414 \mathrm{~nm}$ with a QY of 5.6\%, and the presence of $\mathrm{Eu}^{3+}$ did not influence the FLE of the QDs. This sensor recognized the target molecules by three different mechanisms: $i$ ) Excitation spectrum of QDs that was overlapped with the absorption spectrum of tetracyclines, which might cause the fluorescence turn-off from the IFE 
of the QDs towards tetracyclines; ii) the conduction bands of the QDs were calculated to be $-2.1 \mathrm{eV}$, which is higher than the conduction bands of different tetracyclines derivatives; therefore, a PET process could take place from QDs towards the target molecules; and iii) tetracyclines had a $\beta$ diketonate configuration within their structures that enabled them to chelate with $\mathrm{Eu}^{3+}$, which was accompanied by the energy transfer, defined by the authors as the antenna effect; this caused the enhanced red fluorescence of $\mathrm{Eu}^{3+}$ at $616 \mathrm{~nm}$ (ratiometric dual emission). Likewise, the abovementioned mechanisms were used in designing the sensors for detecting heavy metal ions. For example, Wang and co-workers reported the synthesis of dual-emission SQDs from colloidal methods using a binary mixture of $\mathrm{Cd}$ and Te for the detection of $\mathrm{Cu}$ ions. These green emissive SQDs showed two well-resolved emission peaks at 550 and $650 \mathrm{~nm}$ in the presence of $\mathrm{Cu}^{2+}$ under a single wavelength excitation, which allowed them to explore a ratiometric probe with a linear range, which resided between $5 \times 10^{-2}$ to $5 \times 10^{-1} \mu \mathrm{M}$, with a LOD of $0.001 \mu \mathrm{M}$ [64].

\section{Application of CDs in Heavy Metal Sensing}

One of the most important sensing applications of CDs corresponds to the recognition of heavy metals with environmental and biological concerns. Some recent studies reported that the use of CDs with passivation agents could detect $\mathrm{Hg}^{2+}, \mathrm{Pb}^{2+}, \mathrm{Cu}^{2+}, \mathrm{Fe}^{3+}, \mathrm{Cd}^{2+}$, and $\mathrm{Cr}^{6+}$ ions, as summarized in Table 1. Next, we describe the recent advancements for each metal ion regarding this important issue. 
Table 1 Summary of different synthesized CDs and their applications

\begin{tabular}{|c|c|c|c|c|c|}
\hline $\begin{array}{l}\text { Carbon source and passivation } \\
\text { agents }\end{array}$ & Synthetic approach & Sensing & $\begin{array}{l}\text { Linear range } \\
(\mu \mathrm{M})\end{array}$ & LOD $(\mu \mathrm{M})$ & Ref. \\
\hline $\begin{array}{l}\text { Citric acid with glutathione or } \\
\text { thiourea }\end{array}$ & Microwave method & $\mathrm{Hg}^{2+}$ (FLE turn-off by PET mechanism) & $5-50$ & 1.78 & [65] \\
\hline Citric acid with ethylenediamine & Autoclave and heating & $\mathrm{Hg}^{2+}$ (FLE turn-on by FRET mechanism) & $0.005-0.2$ & 0.0026 & [66] \\
\hline \multirow[t]{2}{*}{ Tartaric acid and L-arginine } & Solvothermal method & $\mathrm{Hg}^{2+}$ (FLE turn-off by static mechanism ${ }^{\mathrm{b}}$ ) & $0-5$ & 0.017 & [67] \\
\hline & & $\mathrm{Fe}^{3+}\left(\mathrm{FLE}\right.$ turn-off by static mechanism $\left.{ }^{\mathrm{b}}\right)$ & $0-70$ & 0.50 & \\
\hline \multirow[t]{2}{*}{ Gardenia fruit } & Hydrothermal method & $\mathrm{Hg}^{2+}\left(\right.$ FLE turn-off by static mechanism $\left.{ }^{b}\right)$ & $2-20$ & 0.320 & [68] \\
\hline & & Cysteine (FLE turn-on mechanism) & $0.1-2.0$ & 0.271 & \\
\hline \multirow[t]{2}{*}{ Sodium citrate and polyacrylamide } & Hydrothermal method & $\mathrm{Pb}^{2+}$ (FLE turn-off by IFE mechanism) & $0.0167-1.0$ & 0.0046 & [69] \\
\hline & & $\begin{array}{l}\text { PPi (FLE turn-on by disruption of IFE } \\
\text { mechanism) }\end{array}$ & $0.67-26.7$ & 0.054 & \\
\hline leaves of Ocimum sanctum & Hydrothermal method & $\mathrm{Pb}^{2+}($ FLE turn-off by PET mechanism) & $0.01-1.0$ & 0.00059 & [70] \\
\hline \multirow[t]{2}{*}{$\begin{array}{l}\text { Neutral red and 3-aminopropyl } \\
\text { triethoxysilane }\end{array}$} & Solvothermal method & $\mathrm{Cu}^{2+}$ (FLE turn-off by PET mechanism) & $10-90$ & 0.53 & [71] \\
\hline & & $\begin{array}{l}\text { L-Cys (FLE turn-on by disruption of } \\
\text { PETmechanism) }\end{array}$ & 20-100 & 0.41 & \\
\hline Chitosan and dansyl & Hydrothermal method & $\mathrm{Fe}^{3+}$ (FLE turn-off by PET mechanism) & $0-100$ & 1.23 & [72] \\
\hline Maize starch & Solvothermal method & $\mathrm{Fe}^{3+}$ (FLE turn-off by PET mechanism) & $0.1-50$ & 0.1 & [73] \\
\hline
\end{tabular}




\begin{tabular}{|c|c|c|c|c|c|}
\hline Citric acid and L-cysteine & Hydrothermal method & $\mathrm{Fe}^{3+}$ (FLE turn-off by RDE mechanism) & $0.1-10$ & 0.083 & {$[74]$} \\
\hline Trisodium citrate and phosphoric acid & Hydrothermal method & $\mathrm{Fe}^{3+}\left(\right.$ FLE turn-off by static mechanism $\left.{ }^{b}\right)$ & $0.020-3.0$ & 0.0095 & {$[75]$} \\
\hline $\begin{array}{l}\text { 2,5-Diaminobenzenesulfonic acid and } \\
\text { 4-aminophenylboronic acid } \\
\text { hydrochloride }\end{array}$ & Hydrothermal method & $\mathrm{Fe}^{3+}\left(\right.$ FLE turn-off by static mechanism $\left.{ }^{\mathrm{b}}\right)$ & $0.3-546$ & 0.090 & {$[76]$} \\
\hline \multirow[t]{2}{*}{ E. coli } & Hydrothermal method & $\mathrm{Cr}^{6+}$ (FLE turn-off by IFE mechanism) & $0-25$ & 0.06475 & {$[77]$} \\
\hline & & 4-NFa (FLE turn-off by IFE mechanism) & $0-50$ & 0.08889 & \\
\hline $\begin{array}{l}\text { Polyethyleneimine and } \mathrm{P} \text { - } \\
\text { phenylenediamine }\end{array}$ & Pyrolysis & $\begin{array}{c}\mathrm{Cr}^{6+} \text { (FLE turn-off by IFE mechanism and } \\
\text { electron/hole recombination) }\end{array}$ & $2.0-80.0$ & 0.39 & [78] \\
\hline \multirow{2}{*}{$\begin{array}{l}\text { Orange peels (CDs modified with } \\
\text { EDTA) }\end{array}$} & Hydrothermal method & $\mathrm{Cr}^{6+}$ (FLE turn-off by IFE mechanism) & $10-50$ & 0.010 & [79] \\
\hline & & $\begin{array}{c}A^{c} \text { (FLE turn-on by disruption of IFE } \\
\text { mechanism) }\end{array}$ & $0.1-400$ & 0.1 & \\
\hline
\end{tabular}

${ }^{a}$ 4-Nitrophenol; ${ }^{b}$ Static quenching mechanism occurs when the molecules form a complex in the ground state, then, $\pi$-stacked complexes efficiently suppress fluorescence emission over time scales longer than the fluorescence lifetime; ${ }^{c}$ Ascorbic acid. 


\subsection{CDs in Mercury lon Sensing}

The detection of $\mathrm{Hg}^{2+}$ ions is very important due to their toxicity and environmental risks. Diverse diseases are associated with the accumulation of $\mathrm{Hg}^{2+}$ ions in the human body, such as Minamata disease, which is related to severe neurological pathologies including motion disorders, ataxia, and paroxysmal convulsion [80]. Different studies have been focused on $\mathrm{Hg}^{2+}$ detection in aqueous solutions [81], food [82], and living cells [83]. Yang and co-workers reported the bright bluefluorescent $\mathrm{N}$-doped $\mathrm{CDs}$ that were synthesized from citric and folic acid [84]. CDs were demonstrated to be a sensitive fluorescent system for detecting $\mathrm{Hg}^{2+}$ in an aqueous solution through an ultrafast electron transfer reaction, with a low limit of detection (LOD) of $0.124 \mu \mathrm{M}$. Interestingly, the fluorescence intensities exhibited a $\mathrm{pH}$-dependent behaviour when CDs were excited at the $\lambda_{\text {exc }}$ of $390 \mathrm{~nm}$, with an excellent correlation between FLE and $\mathrm{pH}$ ranging from 6.8-7.8. Considering the tunable emission of $\mathrm{CDs}$, different fluorescent systems for the detection of $\mathrm{Hg}^{2+}$ have been synthesized, with emission in many regions of the visible spectrum. Teng and co-workers developed $\mathrm{N}$-doped CDs with an efficient green emission that was quenched (turn-off) through PET mechanism in the presence of $\mathrm{Hg}^{2+}$ ions, showing a LOD of $0.89 \mu \mathrm{M}$ in water. Interestingly, the fluorescence could be recovered (turn-on) when the iodide ions were present in the solution, which could produce $\mathrm{Hgl}_{2}$, leading to a LOD for iodide ion detection of $0.50 \mu \mathrm{M}$ [85]. In recent years, several studies demonstrating natural products as a highly abundant carbon source for fabricating CDs have been reported. Citrus juice is a good alternative because of its high content of citric acid. Belachew and co-workers synthesized the bright blue-fluorescent $\mathrm{N}$-doped CDs from citrus lemon juice as a carbon source and ethylenediamine as the passivation agent via hydrothermal treatment at $200{ }^{\circ} \mathrm{C}$ [86]. These CDs showed a narrow size distribution (particle size of $\sim 3 \mathrm{~nm}$ ), with a high QY of 31\%, high selectivity and sensitivity towards $\mathrm{Hg}^{2+}$ ions, a LOD of $0.0053 \mu \mathrm{M}$, and a limit of quantification (LOQ) of $0.0183 \mu \mathrm{M}$. Other CDs have also been synthesized for $\mathrm{Hg}^{2+}$ detection and are summarized in Table 1 [65-68].

\subsection{CDs in Lead lon Sensing}

$\mathrm{Pb}^{2+}$ ions are of great concern as they cause high toxicity in the human body and environmental damage [87]. Kumar and co-workers reported the synthesis of biocompatible $\mathrm{CDs}$ for $\mathrm{Pb}^{2+}$ detection using a green methodology from Pearl Millet Seed by a hydrothermal approach [88]. The optical properties of the CDs allowed them to recognize $\mathrm{Pb}^{2+}$ selectively with a LOD of $0.18 \mathrm{nM}$ through either a colorimetric or fluorometric methodology, which resulted in the modulation of a PCT process. As can be seen, the use of biomass is a great alternative for obtaining CDs; for example, it has been reported that the use of extracts of bamboo leaves for the development of nanohybrids of $\mathrm{CDs}$ with multi-emission luminescence for highly sensitive detection of sub-nanomolar $\mathrm{Pb}^{2+}$ and $\mathrm{Hg}^{2+}$ ions with a LOD of 0.14 and $0.22 \mathrm{nM}$ (ratiometric probe), respectively [89]. Likewise, several studies using fluorescence sensors based on $\mathrm{CDs}$ for the detection of $\mathrm{Pb}^{2+}$ ions have been reported so far (Table 1) $[69,70]$.

\subsection{CDs in Copper lon Sensing}

The oxidized copper species ( $\mathrm{Cu}^{1+}$ and $\mathrm{Cu}^{2+}$ ions), which are among the most studied and versatile catalytic systems [90], play a key role in many biological processes and result in neurodegenerative 
diseases when the cellular homeostasis is altered by the copper ions [91]. However, an excess of $\mathrm{Cu}^{2+}$ ions in the human body, which could enter through contaminated water, can result in different diseases including liver or kidney damage and gastrointestinal disturbance [92]. Solanki and coworkers reported the synthesis of highly fluorescent $\mathrm{N}, \mathrm{S}$ co-doped CDs from banana (Musa acuminata) juice for the detection of $\mathrm{Cu}^{2+}$ ions. The spherical $\mathrm{CDs}$ showed high QY (32\%), displaying the detection of $\mathrm{Cu}^{2+}$ through a "turn-off" response, with a LOD of $0.3 \mu \mathrm{g} / \mathrm{mL}$ in a concentration range of $1-800 \mu \mathrm{g} / \mathrm{mL}$. This "turn-off" response likely resulted from the PCT mechanism; upon coordination of $\mathrm{Cu}^{2+}$ to the functional groups $(-\mathrm{OH},-\mathrm{COOH}, \mathrm{C}=0)$ on the $\mathrm{CD}$ surface, a charge transfer between NS-CDs and $\mathrm{Cu}^{2+}$ ions was possible, showing non-radiative recombination, and, therefore, the fluorescence quenching happened [93]. The activation of Metal-Organic Frameworks (MOFs) by treatment with CDs was explored in recent years for the development of selective sensors towards the metal ions. Thus, the activation of MOFs based on 2-amino-terephthalic acid using the CDs obtained from glucan by a hydrothermal method led to enhanced fluorescence, which was quenched with the removal of $\mathrm{CDs}$ by $\mathrm{Cu}^{2+}$ and $\mathrm{Fe}^{3+}$ ions. The detection method using this fluorescence "on/off" probe showed a LOD of $1.3 \mathrm{ppb}$ and $2.3 \mathrm{ppb}$ for $\mathrm{Cu}^{2+}$ and $\mathrm{Fe}^{3+}$ ions, respectively [94]. Also, other different fluorescence modes were used to detect $\mathrm{Cu}^{2+}$ ions. Liu and co-workers synthesized Si-doped CDs using a fluorescent "on-off-on" mode for the detection of $\mathrm{Cu}^{2+}$ and Lcysteine (L-Cys), wherein, upon recognition of $\mathrm{Cu}^{2+}$, the fluorescence was quenched by an electron transfer process. However, fluorescence could be recovered by the addition of L-Cys (Table 1, ref [71]).

\subsection{CDs in Iron Ion Sensing}

Similar to the $\mathrm{Cu}^{2+}$ ions, the detection of $\mathrm{Fe}^{3+}$ ions is also very important because they play a key role in different biological processes, such as oxygen transportation, enzymatic catalysis, and cell proliferation [95]. Considering that a disproportion of this metal ion can lead to many diseases, it is important to evaluate $\mathrm{Fe}^{3+}$ ion levels in the drinking water [96]. A fluorescent "on-off-on" mode was employed to determine $\mathrm{Fe}^{3+}$ ions using $\mathrm{N}$ and $\mathrm{P}$ co-doped CDs with a high QY of $84 \%$. Interestingly, $\mathrm{Fe}^{3+}$ led to quenching of the fluorescence through PET from CDs toward the $3 \mathrm{~d}$ orbital of $\mathrm{Fe}^{3+}$, which was recovered when catecholamine neurotransmitters were employed, demonstrating the versatility of these $\mathrm{CDs}$ as sensors. For the detection of $\mathrm{Fe}^{3+}$, co-doped $\mathrm{CDs}$ showed a linear range between $0-40 \mu \mathrm{M}$ and a LOD of $0.2 \mu \mathrm{M}$ that was below the recommended $\mathrm{Fe}^{3+}$ levels in drinking water $(5.4 \mu \mathrm{M})$ [96]. For dopamine, one of the most important catecholamine neurotransmitters, the linear range was between 4-15 $\mu \mathrm{M}$, with a LOD of $0.1 \mu \mathrm{M}$. Recently, Geng and co-workers also reported the synthesis of co-doped CDs for the detection of $\mathrm{Fe}^{3+}$ ions together with Escherichia coli. CDs were co-doped with nitrogen and boron and resulted in a blue FLE. The recognition of $E$. coli was possible due to the presence of charged groups on the $C D$ surface that could bind to the bacterial cells through electrostatic interaction. The LOD for $\mathrm{Fe}^{3+}$ was $0.74 \mu \mathrm{M}$ and that for $E$. coli was 165 CFUs (colony forming units)/mL. The sensor was tested with real samples of tap water and orange juice, proving to be practical and effective [97]. Recently, several other studies on the fluorescence sensors based on doped CDs have been reported using different carbon sources, such as chitosan and dansyl [72], maize starch [73], citric acid and L-cysteine [74], trisodium citrate and phosphoric acid [75], benzene sulfonic and phenylboronic acid derivatives [76], etc. A brief description of these studies is provided in Table 1. 


\subsection{CDs in Cadmium and Chromium Ion Sensing}

Among other metal ions with toxicological and environmental concerns, $\mathrm{Cd}^{2+}$ and $\mathrm{Cr}^{6+}$ are important $[98,99]$. The investigation of fluorescence sensors for the detection of $\mathrm{Cd}^{2+}$ ions has not been widely explored. Nanohybrids based on CDs and gold nanocluster (AuNCs) have been developed as ratiometric fluorescent probes for the detection of $\mathrm{Cd}^{2+}$ ions and ascorbic acid [100]. CDs obtained from alanine and histidine by hydrothermal treatment afforded blue emissive particles with a QY of $40.8 \%$. The CDs/AuNCs-based system exhibited high selectivity toward $\mathrm{Cd}^{2+}$ with a LOD of $32.5 \mathrm{nM}$, leading to fluorescence quenching. However, the fluorescence was

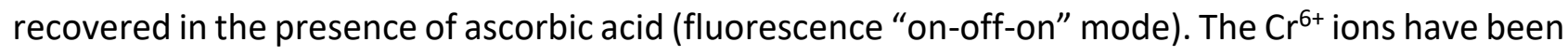
more extensively studied in comparison to the $\mathrm{Cd}^{2+}$ ions. $\mathrm{Li}$ and co-workers reported the green synthesis of CDs from flax straw, which showed a QY of $20.7 \%$. The CDs/AuNCs used for the detection of $\mathrm{Cd}^{2+}$ led to $\mathrm{Cr}^{6+}$ detection through a "turn-off" response. Using a fluorescence "on-offon" mode, these CDs also detected ascorbic acid based on the reduction of $\mathrm{Cr}^{6+}$ to $\mathrm{Cr}^{3+}$ by this acid, and the FLE was recovered as well [101]. LOD values for $\mathrm{Cr}^{6+}$ ions and ascorbic acid were 0.19 and $0.35 \mu \mathrm{M}$, respectively. On the other hand, the use of $\mathrm{P} / \mathrm{N}$ dual-doped $\mathrm{CDs}$ for the development of a sensor for $\mathrm{Cr}^{6+}$ ions and ascorbic acid through a fluorescence "on-off-on" mode led to a lower LOD for $\mathrm{Cr}^{6+}(\mathrm{LOD}=0.023 \mu \mathrm{M})$, while the LOD was higher for ascorbic acid (LOD = $\left.1.35 \mu \mathrm{M}\right)$ [102]. Likewise, Chen and co-workers reported the synthesis of $\mathrm{N}$-doped CQDs that were immobilized in hydrophilic silica hydrogels for the selective detection of $\mathrm{Cr}^{6+}$ and $\mathrm{Re}^{4+}$ ions by a turn-off fluorescent sensing platform based on the IFE mechanism. LOD values for $\mathrm{Cr}^{6+}$ and $\mathrm{Re}^{4+}$ ions were about $65 \mathrm{nM}$ and $2.3 \mu \mathrm{M}$, respectively [103]. It is worth noting that more serious efforts were put into the detection of $\mathrm{Cr}^{6+}$ ions instead of $\mathrm{Cr}^{3+}$ ions because the former shows higher toxicity. A GQD sensor based on the FLE turn-off mechanism was reported for the detection of $\mathrm{Fe}^{3+}, \mathrm{Cr}^{3+}$, and $\mathrm{Pb}^{2+}$ ions in aqueous media, with low LOD values of 50,100 , and $100 \mathrm{nM}$, respectively [23]. Different sensing systems for $\mathrm{Cr}^{6+}$ ions have been reported using different carbon sources and presenting low LOD [77-79].

The role of CDs has also been studied for the detection of other metals such as $\mathrm{Ag}^{+}[104,105]$ and $\mathrm{Zn}^{2+}$ ions [106].

\section{Conclusions}

The monitoring of heavy metal ions having toxicological and environmental impacts is an important issue nowadays. The increase in anthropogenic activities, such as mining, agriculture, and crop eradication, can release huge amounts of these metal ions into the ecosystems. CDs have emerged as an efficient alternative to detect heavy metal ions due to their extraordinary FLE properties; in addition, they can perform without generating a negative impact on the environment, considering their low toxicity and biocompatibility. Although tremendous progress has been made for decreasing the LOD values in aqueous solution for heavy metal detection, there are still many barriers to overcome, which include difficult preparation, purification, and characterization, low quantum yields, selectivity, and reproducibility.

\section{Acknowledgments}

CAEG acknowledges the postdoctoral program VIE-UIS-Conv. 2019. 


\section{Author Contributions}

Authors contributed equally to this work.

\section{Funding}

This work was supported by Colombian Institute for Science and Research (COLCIENCIAS) under the project No. RC-007-2017, Cod. 110274558597.

\section{Competing Interests}

The authors have declared that no competing interests exist.

\section{References}

1. Echeverry CA, Castro E. Organic and organic-inorganic solar cells: From bulk heterojunction to perovskite Solar cells. Int J Chem Res. 2018; 1: 1-8.

2. Gust D, Moore TA, Moore AL. Mimicking photosynthetic solar energy transduction. Acc Chem Res. 2001; 34: 40-48.

3. Echeverry-Gonzalez CA, Puerto-Galvis CE, Borca CH, Mosquera MA, Luis-Robles AF, Kouznetsov VV. Optimization of the synthesis of quinoline-based neutral cyclometalated iridium complexes via microwave irradiation: Design of light harvesting and emitting complexes using bulky quinolines. Org Chem Front. 2019; 6: 3374-3382.

4. Cayuela A, Soriano ML, Carrillo-Carrión C, Valcárcel M. Semiconductor and carbon-based fluorescent nanodots: The need for consistency. Chem Commun. 2016; 52: 1311-1326.

5. Díaz-González M, de la Escosura-Muñiz A, Fernandez-Argüelles MT, Alonso FJ, Costa-Fernandez JM. Quantum dot bioconjugates for diagnostic applications. Top Curr Chem. 2020; 378: 35.

6. Mansur HS, Mansur AA, Curti E, De Almeida M V. Functionalized-chitosan/quantum dot nanohybrids for nanomedicine applications: Towards biolabeling and biosorbing phosphate metabolites. J Mater Chem B. 2013; 1: 1696-1711.

7. Marković ZM, Labudová $M$, Danko $M$, Matijašević $D$, Mičušík $M$, Nádaždy $V$, et al. Highly efficient antioxidant $\mathrm{F}$ - and $\mathrm{Cl}$ - doped carbon quantum dots for bioimaging. ACS Sustain Chem Eng. 2020; 8: 16327-16338.

8. Matea CT, Mocan T, Tabaran F, Pop T, Mosteanu O, Puia C, et al. Quantum dots in imaging, drug delivery and sensor applications. Int J Nanomedicine. 2017; 12: 5421-5431.

9. Russo C, Apicella B, Ciajolo A. Blue and green luminescent carbon nanodots from controllable fuel-rich flame reactors. Sci Rep. 2019; 9: 14566.

10. Guo $T$, Wu Y, Lin $Y, X u X$, Lian $H$, Huang GM, et al. Black phosphorus quantum dots with renal clearance property for efficient photodynamic therapy. Small. 2018; 14: 1702815.

11. Ekimov Al, Onuschenko AA. Quantum size effect in three-dimensional microscopic semiconductors. JETP Lett. 1981; 34: 363.

12. Reed MA, Randall JN, Aggarwal RJ, Matyi RJ, Moore TM, Wetsel AE. Observation of discrete electronic states in a zero-dimensional semiconductor nanostructure. Phys Rev Lett. 1988; 60: 535.

13. Biju V. Chemical modifications and bioconjugate reactions of nanomaterials for sensing, imaging, drug delivery and therapy. Chem Soc Rev. 2014; 43: 744-764. 
14. Kagan CR, Bassett LC, Murray CB, Thompson SM. Colloidal quantum dots as platforms for quantum information science. Chem Rev. 2021; 121: 3186-3233.

15. Semeniuk $M, Y i Z H$, Poursorkhabi $V$, Tjong J, Jaffer $S$, Lu ZH, et al. Future perspectives and review on organic carbon dots in electronic applications. ACS Nano. 2019; 13: 6224-6255.

16. Lim SY, Shen W, Gao ZQ. Carbon quantum dots and their applications. Chem Soc Rev. 2015; 44: 362-381.

17. Bonilla CA, Flórez MH, Velasco DR, Kouznetsov VV. Surface characterization of thiol ligands on CdTe quantum dots: Analysis by ${ }^{1} \mathrm{H}$ NMR and DOSY. New J Chem. 2019; 43: 8452-8458.

18. Liu ML, Chen BB, Li CM, Huang CZ. Carbon dots: Synthesis, formation mechanism, fluorescence origin and sensing applications. Green Chem. 2019; 21: 449-471.

19. DHordjević L, Arcudi F, Prato M. Preparation, functionalization and characterization of engineered carbon nanodots. Nat Protoc. 2019; 14: 2931-2953.

20. Arcudi F, DJordjević L, Prato M. Synthesis, separation, and characterization of small and highly fluorescent nitrogen-doped carbon nanodots. Angew Chem Int Ed Engl. 2016; 128: 2147-2152.

21. Sun HJ, Wu L, Wei WL, Qu XG. Recent advances in graphene quantum dots for sensing. Mater Today. 2013; 16: 433-442.

22. Mansuriya BD, Altintas Z. Applications of graphene quantum dots in biomedical sensors. Sensors. 2020; 20: 1072.

23. Raj SK, Yadav V, Bhadu GR, Patidar R, Kumar M, Kulshrestha V. Synthesis of highly fluorescent and water soluble graphene quantum dots for detection of heavy metal ions in aqueous media. Environ Sci Pollut Res. 2020: 24: 1-7.

24. Iannazzo D, Celesti C, Espro C. Recent advances on graphene quantum dots as multifunctional nanoplatforms for cancer treatment. Biotechnol J. 2021; 16: 1900422.

25. Tajik S, Dourandish Z, Zhang KQ, Beitollahi H, Van Le Q, Jang HW, et al. Carbon and graphene quantum dots: A review on syntheses, characterization, biological and sensing applications for neurotransmitter determination. RSC Adv. 2020; 10: 15406-15429.

26. Xu HH, Yan LH, Nguyen V, Yu Y, Xu YM. One-step synthesis of nitrogen-doped carbon nanodots for ratiometric $\mathrm{pH}$ sensing by femtosecond laser ablation method. Appl Surf Sci. 2017; 414: 238243.

27. Doñate-Buendia C, Torres-Mendieta R, Pyatenko A, Falomir E, Fernández-Alonso M, MínguezVega G. Fabrication by laser irradiation in a continuous flow jet of carbon quantum dots for fluorescence imaging. ACS Omega. 2018; 3: 2735-2742.

28. Zhang QH, Sun XF, Ruan H, Yin KY, Li HG. Production of yellow-emitting carbon quantum dots from fullerene carbon soot. Sci China Mater. 2017; 60: 141-150.

29. Zhang YF, Park M, Kim HY, Ding B, Park S-J. A facile ultrasonic-assisted fabrication of nitrogendoped carbon dots/BiOBr up-conversion nanocomposites for visible light photocatalytic enhancements. Sci Rep. 2017; 7: 45086.

30. Dang H, Huang LK, Zhang Y, Wang CF, Chen S. Large-scale ultrasonic fabrication of white fluorescent carbon dots. Ind Eng Chem Res. 2016; 55: 5335-5341.

31. Liu ML, Xu YH, Niu FS, Gooding JJ, Liu JQ. Carbon quantum dots directly generated from electrochemical oxidation of graphite electrodes in alkaline alcohols and the applications for specific ferric ion detection and cell imaging. Analyst. 2016; 141: 2657-2664. 
32. Fu Y, Gao GY, Zhi JF. Electrochemical synthesis of multicolor fluorescent N-doped graphene quantum dots as a ferric ion sensor and their application in bioimaging. J Mater Chem B. 2019; 7: 1494-1502.

33. Ma CB, Zhu ZT, Wang HX, Huang $X$, Zhang $X$, Qi $X$, et al. A general solid-state synthesis of chemically-doped fluorescent graphene quantum dots for bioimaging and optoelectronic applications. Nanoscale. 2015; 7: 10162-10169.

34. Wang HB, Ning GQ, He X, Ma XL, Yang F, Xu ZM, et al. Carbon quantum dots derived by direct carbonization of carbonaceous microcrystals in mesophase pitch. Nanoscale. 2018; 10: 2149221498.

35. Ko NR, Nafiujjaman M, Cherukula K, Lee SJ, Hong SJ, Lim HN, et al. Microwave-assisted synthesis of biocompatible silk fibroin-based carbon quantum dots. Part Part Syst Charact. 2018; 35: 1700300.

36. Rodríguez-Padrón D, Algarra M, Tarelho LA, Frade J, Franco A, de Miguel G, et al. Catalyzed microwave-assisted preparation of carbon quantum dots from lignocellulosic residues. ACS Sustain Chem Eng. 2018; 6: 7200-7205.

37. Maasoumi F, Jansen-van Vuuren RD, Shaw PE, Puttock EV, Nagiri RC, McEwan JA, et al. An external quantum efficiency of $>20 \%$ from solution-processed poly (dendrimer) organic lightemitting diodes. Npj Flex Electron. 2018; 2: 27.

38. Li GM, Li P, Zhuang XM, Ye KQ, Liu Y, Wang Y. Rational design and characterization of heteroleptic phosphorescent complexes for highly efficient deep-red organic light-emitting devices. ACS Appl Mater Interfaces. 2017; 9: 11749-11758.

39. Jiang $B$, Ning $X W$, Gong SL, Jiang $N$, Zhong $C$, Lu ZH, et al. Highly efficient red iridium (III) complexes cyclometalated by 4-phenylthieno 3, 2-c. quinoline ligands for phosphorescent OLEDs with external quantum efficiencies over 20\%. J Mater Chem C. 2017; 5: 10220-10224.

40. Yang XL, Zhou GJ, Wong WY. Functionalization of phosphorescent emitters and their host materials by main-group elements for phosphorescent organic light-emitting devices. Chem Soc Rev. 2015; 44: 8484-8575.

41. Zhao B, Wang ZB, Tan ZA. Deep-blue carbon dots offer high colour purity. Nat Photonics. 2020; 14: $130-131$.

42. Shen HB, Gao Q, Zhang YB, Lin Y, Lin QL, Li ZH, et al. Visible quantum dot light-emitting diodes with simultaneous high brightness and efficiency. Nat Photonics. 2019; 13: 192-197.

43. Yuan FL, Wang YK, Sharma G, Dong YT, Zheng XP, Li PC, et al. Bright high-colour-purity deepblue carbon dot light-emitting diodes via efficient edge amination. Nat Photonics. 2020; 14: 171-176.

44. Zhu SJ, Song YB, Zhao XH, Shao JR, Zhang JH, Yang B. The photoluminescence mechanism in carbon dots (graphene quantum dots, carbon nanodots, and polymer dots): Current state and future perspective. Nano Res. 2015; 8: 355-381.

45. Gharat PM, Chethodil JM, Srivastava AP, Praseetha PK, Pal H, Choudhury SD. An insight into the molecular and surface state photoluminescence of carbon dots revealed through solventinduced modulations in their excitation wavelength dependent emission properties. Photochem Photobiol Sci. 2019; 18: 110-119.

46. Cushing SK, Li M, Huang FQ, Wu NQ. Origin of strong excitation wavelength dependent fluorescence of graphene oxide. ACS Nano. 2014; 8: 1002-1013. 
47. Józefowicz M, Heldt JR. Excitation-wavelength dependent fluorescence of ethyl 5-(4aminophenyl)-3-amino-2, 4-dicyanobenzoate. J Fluoresc. 2011; 21: 239-245.

48. Echeverry-Gonzalez CA, Ortiz A, Insuasty B. Rhodanine-based light-harvesting sensitizers: A rational comparison between 2-(1, 1-dicyanomethylene) rhodanine and rhodanine-3-acetic acid. New J Chem. 2019; 43: 8781-8787.

49. Demchenko AP. The red-edge effects: 30 years of exploration. Luminescence. 2002; 17: 19-42.

50. Zhu PP, Tan KJ, Chen Q, Xiong J, Gao LX. Origins of efficient multiemission luminescence in carbon dots. Chem Mater. 2019; 31: 4732-4742.

51. Zhang TY, Zhao FF, Li L, Qi B, Zhu D, Lü JH, et al. Tricolor white-light-emitting carbon dots with multiple-cores@shell structure for WLED application. ACS Appl Mater Interfaces. 2018; 10: 19796-19805.

52. Chung SH, Revia RA, Zhang MQ. Graphene quantum dots and their applications in bioimaging, biosensing, and therapy. Adv Mater. 2019; 1904362. DOI: 10.1002/adma.201904362.

53. Mao ZF, Wang MD, Liu JB, Liu LJ, Lee SM, Leung CH, et al. A long lifetime switch-on iridium (III) chemosensor for the visualization of cysteine in live zebrafish. Chem Commun. 2016; 52: 44504453.

54. Liu JL, Liu Y, Liu Q, Li CY, Sun LN, Li FY. Iridium (III) complex-coated nanosystem for ratiometric upconversion luminescence bioimaging of cyanide anions. J Am Chem Soc. 2011; 133: 1527615279.

55. Wang YT, Hu S, Zhang Y, Gong H, Sun R, Mao W, et al. A colorimetric $\mathrm{Pb}^{2+}$ chemosensor: Rapid naked-eye detection, high selectivity, theoretical insights, and applications. J Photochem Photobiol A Chem. 2018; 355: 101-108.

56. Zhang QS, Zhang J, Zuo HJ, Wang CY, Shen YJ. A novel near-infrared chemosensor for mercury ion detection based on D-A structure of triphenylamine and benzothiadiazole. Tetrahedron. 2017; 73: 2824-2830.

57. Tigreros A, Portilla J. Recent progress in chemosensors based on pyrazole derivatives. RSC Adv. 2020; 10: 19693-19712.

58. Tigreros A, Rosero HA, Castillo JC, Portilla J. Integrated pyrazolo 1, 5-a.pyrimidine--hemicyanine system as a colorimetric and fluorometric chemosensor for cyanide recognition in water. Talanta. 2019; 196: 395-401.

59. Echeverry-Gonzalez CA, Villamizar MC, Kouznetsov VV. Remarkable selectivity of the 2arylquinoline-based acyl hydrazones toward copper salts: Exploration of their catalytic applications in the copper catalysed $\mathrm{N}$-arylation of Indole derivatives and C1-Alkynylation of Tetrahydroisoquinolines by $A^{3}$ Reaction. New J Chem. 2021; 45, 243-250.

60. Devi $P$, Rajput $P$, Thakur A, Kim KH, Kumar $P$. Recent advances in carbon quantum dot-based sensing of heavy metals in water. Trends Anal Chem. 2019; 114: 171-195.

61. Chen S, Yu YL, Wang JH. Inner filter effect-based fluorescent sensing systems: A review. Anal Chim Acta. 2018; 999: 13-26.

62. Sun XC, Lei Y. Fluorescent carbon dots and their sensing applications. Trends Anal Chem. 2017; 89: 163-180.

63. Yang KR, Jia P, Hou JJ, Bu T, Sun XY, Liu YN, et al. Innovative dual-emitting ratiometric fluorescence sensor for tetracyclines detection based on boron nitride quantum dots and europium ions. ACS Sustain Chem Eng. 2020; 8: 17185-17193. 
64. Yao JL, Zhang K, Zhu HJ, Ma F, Sun MT, Yu H, et al. Efficient ratiometric fluorescence probe based on dual-emission quantum dots hybrid for on-site determination of copper ions. Anal Chem. 2013; 85: 6461-6468.

65. Pajewska-Szmyt M, Buszewski B, Gadzała-Kopciuch R. Sulphur and nitrogen doped carbon dots synthesis by microwave assisted method as quantitative analytical nano-tool for mercury ion sensing. Mater Chem Phys. 2020; 242: 122484.

66. Cui X, Zhu L, Wu J, Hou Y, Wang PY, Wang ZN, et al. A fluorescent biosensor based on carbon dots-labeled oligodeoxyribonucleotide and graphene oxide for mercury (II) detection. Biosens Bioelectron. 2015; 63: 506-512.

67. Zhu J, Chu H, Wang T, Wang C, Wei Y. Fluorescent probe based nitrogen doped carbon quantum dots with solid-state fluorescence for the detection of $\mathrm{Hg}^{2+}$ and $\mathrm{Fe}^{3+}$ in aqueous solution. Microchem J. 2020; 158: 105142.

68. Sun D, Liu TT, Wang CF, Yang LF, Yang SK, Zhuo KL. Hydrothermal synthesis of fluorescent carbon dots from gardenia fruit for sensitive on-off-on detection of $\mathrm{Hg}^{2+}$ and cysteine. Spectrochim Acta A Mol Biomol Spectrosc. 2020; 240: 118598.

69. Liu YL, Zhou QX, Yuan YY, Wu YL. Hydrothermal synthesis of fluorescent carbon dots from sodium citrate and polyacrylamide and their highly selective detection of lead and pyrophosphate. Carbon. 2017; 115: 550-560.

70. Kumar A, Chowdhuri AR, Laha D, Mahto TK, Karmakar P, Sahu SK. Green synthesis of carbon dots from Ocimum sanctum for effective fluorescent sensing of $\mathrm{Pb}^{2+}$ ions and live cell imaging. Sens Actuators B Chem. 2017; 242: 679-686.

71. Zan MH, Li C, Zhu DM, Rao L, Meng QF, Chen B, et al. A novel "on-off-on" fluorescence assay for the discriminative detection of $\mathrm{Cu}$ (II) and L-cysteine based on red-emissive Si-CDs and cellular imaging applications. J Mater Chem B. 2020; 8: 919-927.

72. Tian H, Dai YC, Fu WZ, Liu HF, Li MT, Lv MY, et al. Dansyl-modified carbon dots with dualemission for $\mathrm{pH}$ sensing, $\mathrm{Fe}^{3+}$ ion detection and fluorescent ink. RSC Adv. 2020; 10: 36971-36979.

73. Dong GH, Lang K, Ouyang H, Zhang WZ, Bai LM, Chen SJ, et al. Facile synthesis of N, P-doped carbon dots from maize starch via a solvothermal approach for the highly sensitive detection of $\mathrm{Fe}^{3+}$. RSC Adv. 2020; 10: 33483-33489.

74. Chen Z, Xu X, Meng D, Jiang H, Zhou Y, Feng S, et al. Dual-emitting N/S-doped carbon dots-based ratiometric fluorescent and light scattering sensor for high precision fetection of Fe (III) ions. J Fluoresc. 2020; 30: 1007-1013.

75. Kalaiyarasan G, Joseph J, Kumar P. Phosphorus-doped carbon quantum dots as fluorometric probes for iron detection. ACS Omega. 2020; 5: 22278-22288.

76. Liu YH, Duan WX, Song W, Liu JJ, Ren CL, Wu J, et al. Red emission B, N, S-co-doped carbon dots for colorimetric and fluorescent dual mode detection of Fe3+ ions in complex biological fluids and living cells. ACS Appl Mater Interfaces. 2017; 9: 12663-12672.

77. Wang S, Tu Y, Qin K, Yuan X, Chen W, Wei Y, et al. Bacterium-derived carbon dots as a novel "turn-on-on-off-on" sensor for $\mathrm{Cr}(\mathrm{VI})$ and 4-nitrophenol detection based on inner filter effect mechanism. Nano. 2020; 15: 2050074.

78. Zheng XC, Ren ST, Gai QX, Liu WJ. Carbon dot/carbon nitride composites fluorescent probe for the highly selective detection of $\mathrm{Cr}$ (VI) ions. J Photochem Photobiol A Chem. 2020; 400: 112711. 
79. Wang M, Shi R, Gao MJ, Zhang KL, Deng LL, Fu QF, et al. Sensitivity fluorescent switching sensor for $\mathrm{Cr}(\mathrm{VI})$ and ascorbic acid detection based on orange peels-derived carbon dots modified with EDTA. Food Chem. 2020; 318: 126506.

80. Eto K. Pathology of Minamata disease. Toxicol Pathol. 1997; 25: 614-623.

81. Singh A, Eftekhari E, Scott J, Kaur J, Yambem S, Leusch F, et al. Carbon dots derived from human hair for ppb level chloroform sensing in water. Sustain Mater Technol. 2020; 25: e00159.

82. Gan ZY, Hu XT, Huang XW, Li ZH, Zou XB, Shi JY, et al. A dual-emission fluorescence sensor for ultrasensitive sensing mercury in milk based on carbon quantum dots modified with europium (III) complexes. Sensors Actuators B Chem. 2021; 328: 128997.

83. Ren GJ, Meng YX, Zhang Q, Tang MY, Zhu BY, Chai F, et al. Nitrogen-doped carbon dots for the detection of mercury ions in living cells and visualization of latent fingerprints. New J Chem. 2018; 42: 6824-6830.

84. Chang D, Li L, Shi LH, Yang YX. $\mathrm{Hg}^{2+}$ detection, $\mathrm{pH}$ sensing and cell imaging based on bright bluefluorescent N-doped carbon dots. Analyst. 2020; 145: 8030-8037.

85. Hao XL, Pan XH, Gao Y, Wang Y, Guo J, Teng YX. Facile synthesis of nitrogen-doped greenemission carbon dots as fluorescent off-on probes for the highly selective sensing mercury and iodine ions. J Nanosci Nanotechnol. 2020; 20: 2045-2054.

86. Tadesse A, Hagos M, RamaDevi D, Basavaiah K, Belachew N. Fluorescent-nitrogen-doped carbon quantum dots derived from citrus lemon juice: Green synthesis, mercury (II) ion sensing, and live cell imaging. ACS Omega. 2020; 5: 3889-3898.

87. Gorkhali R, Huang K, Kirberger $\mathrm{M}$, Yang JJ. Defining potential roles of $\mathrm{Pb}^{2+}$ in neurotoxicity from a calciomics approach. Metallomics. 2016; 8: 563-578.

88. Chauhan $\mathrm{P}$, Chaudhary S, Kumar R. Biogenic approach for fabricating biocompatible carbon dots and their application in colorimetric and fluorometric sensing of lead ion. J Clean Prod. 2021; 279: 123639.

89. Liu ZY, Jin WY, Wang FX, Li TC, Nie JF, Xiao WC, et al. Ratiometric fluorescent sensing of $\mathrm{Pb}^{2+}$ and $\mathrm{Hg}^{2+}$ with two types of carbon dot nanohybrids synthesized from the same biomass. Sensors Actuators B Chem. 2019; 296: 126698.

90. Echeverry-Gonzalez CA, Kouznetsov VV. Pursuit for simple and efficient ligands promoting copper-catalyzed Ullmann type reactions for $\mathrm{N}$-aryl heterocycles and aromatic amines. In Copper $n$-heterocyclic chemistry. Netherlands: Elsevier; 2020: 399-430.

91. Zeng L, Miller EW, Pralle A, Isacoff EY, Chang CJ. A selective turn-on fluorescent sensor for imaging copper in living cells. J Am Chem Soc. 2006; 128: 10-11.

92. Nordberg GF. Human health effects of metals in drinking water: Relationship to cultural acidification. Environ Toxicol Chem. 1990; 9: 887-894.

93. Chaudhary N, Gupta PK, Eremin S, Solanki PR. One-step green approach to synthesize highly fluorescent carbon quantum dots from banana juice for selective detection of copper ions. J Environ Chem Eng. 2020; 8: 103720.

94. Fan L, Wang YX, Li L, Zhou JG. Carbon quantum dots activated metal organic frameworks for selective detection of $\mathrm{CU}$ (II) and Fe (III). Colloids Surf A Physicochem Eng Asp. 2020; 588: 124378.

95. Kaplan J, Ward DM. The essential nature of iron usage and regulation. Curr Biol. 2013; 23: R642R646. 
96. Le TH, Lee HJ, Kim JH, Park SJ. Detection of ferric ions and catecholamine neurotransmitters via highly fluorescent heteroatom co-doped carbon dots. Sensors. 2020; 20: 3470.

97. Zhang LX, Zhang ZS, Gao ZW, Xie Y, Shu S, Ke Y, et al. Facile synthesis of N, B-co-doped carbon dots with the gram-scale yield for detection of iron (III) and Escherichia coli. Nanotechnology. 2020; 31: 395702.

98. Canton $\mathrm{JH}$, Slooff $\mathrm{W}$. Toxicity and accumulation studies of cadmium $\left(\mathrm{Cd}^{2+}\right)$ with freshwater organisms of different trophic levels. Ecotoxicol Environ Saf. 1982; 6: 113-128.

99. Sun H, Brocato J, Costa M. Oral chromium exposure and toxicity. Curr Environ Health Rep. 2015; 2: 295-303.

100. Niu WJ, Shan D, Zhu RH, Deng SY, Cosnier S, Zhang XJ. Dumbbell-shaped carbon quantum dots/AuNCs nanohybrid as an efficient ratiometric fluorescent probe for sensing cadmium (II) ions and I-ascorbic acid. Carbon. 2016; 96: 1034-1042.

101. Hu GK, Ge L, Li YY, Mukhtar M, Shen B, Yang DS, et al. Carbon dots derived from flax straw for highly sensitive and selective detections of cobalt, chromium, and ascorbic acid. J Colloid Interface Sci. 2020; 579: 96-108.

102. Gong XJ, Liu Y, Yang ZH, Shuang SM, Zhang ZY, Dong C. An "on-off-on" fluorescent nanoprobe for recognition of chromium (VI) and ascorbic acid based on phosphorus/nitrogen dual-doped carbon quantum dot. Anal Chim Acta. 2017; 968: 85-96.

103. Tang CQ, Zhang YM, Han JG, Tian ZQ, Chen L, Chen JQ. Monitoring graphene oxide's efficiency for removing Re (VII) and Cr (VI) with fluorescent silica hydrogels. Environ Pollut. 2020; 262: 114246.

104. Murugesan P, Moses JA, Anandharamakrishnan C. One step synthesis of fluorescent carbon dots from neera for the detection of silver ions. Spectrosc Lett. 2020; 53: 407-415.

105. Qian ZS, Ma JJ, Shan XY, Feng H, Shao LX, Chen JR. Highly luminescent N-doped carbon quantum dots as an effective multifunctional fluorescence sensing platform. Chem Eur J. 2014; 20: 22542263.

106. Yang MX, Tang QL, Meng Y, Liu JJ, Feng TL, Zhao XH, et al. Reversible "off-on" fluorescence of $\mathrm{Zn}^{2+}$-passivated carbon dots: Mechanism and potential for the detection of EDTA and $\mathrm{Zn}^{2+}$. Langmuir. 2018; 34: 7767-7775.

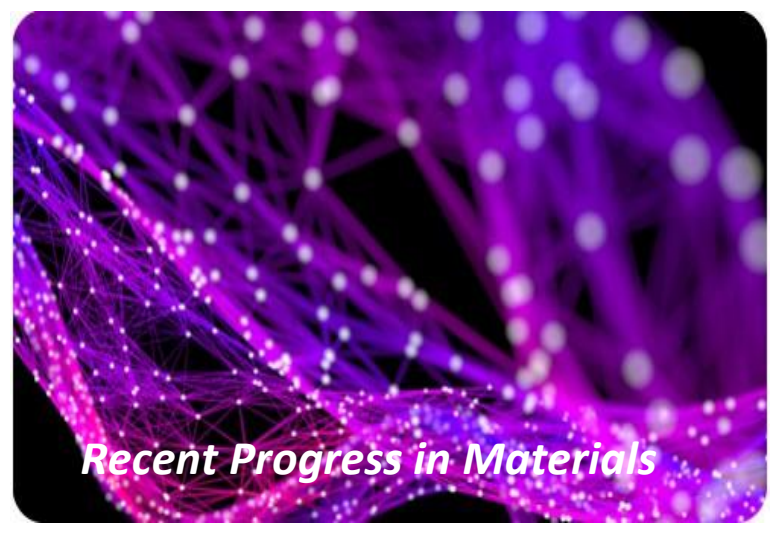

Enjoy Recent Progress in Materials by:

1. Submitting a manuscript

2. Joining in volunteer reviewer bank

3. Joining Editorial Board

4. Guest editing a special issue

For more details, please visit:

http://www.lidsen.com/journals/rpm 